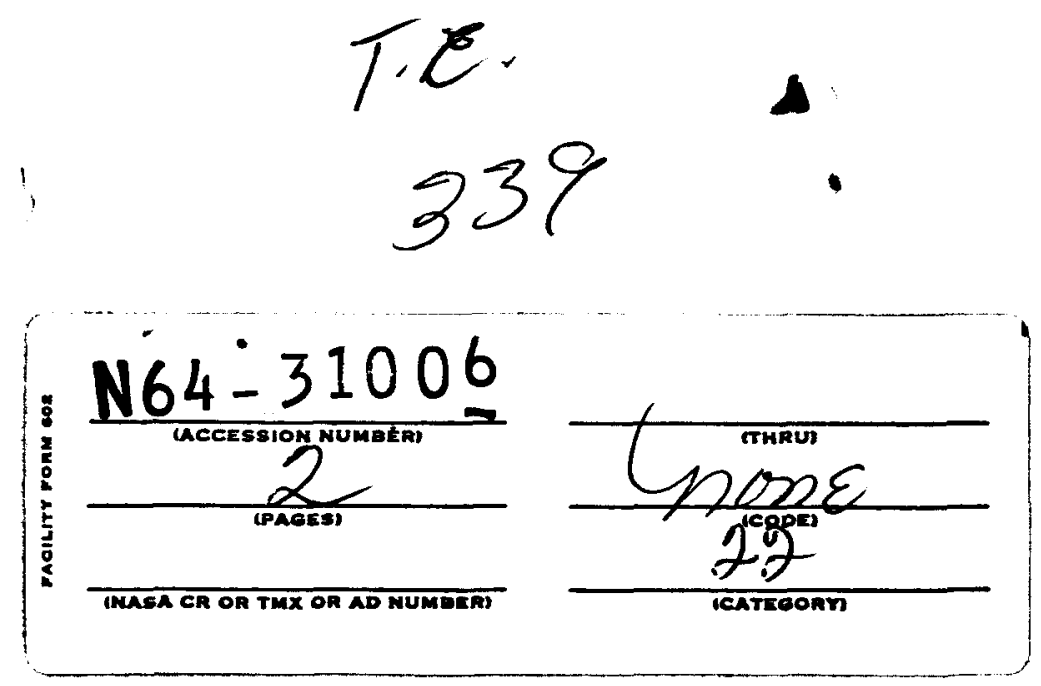

\title{
Simulator Study of a Turn Procedure for Reducing Airspace Requirements 、 : for Supersonic Transports
}

\author{
Richard H. SAwYer* \\ NASA Langley Research Center, Hampton, Va.
}

THE flight of the supersonic transport along airways will differ from present jet-transport flight in the greater airspace that is swept out in making turns at the ground-based radio-navigation facilities which supply bearing and distance information [Very High Frequency Omnidirectional Range, Tactical Air Navigation (VORTAC) stations]. For example, the turning radius for a bank angle of $30^{\circ}$ at a Mach number of 3.0 at cruise altitude is greater than 75 naut miles. Also, continuation of present piloting practice of proceeding through the zone of ambiguity created by the cone of silence over the VORTAC station before initiating the turn will further increase airspace usage. At cruise altitude for the supersonic transport, the zone of ambiguity can vary from 5-25 naut miles depending on the antenna design. An investigation to study the airspace requirements for the supersonic transport in making changes in heading at a VORTAC station and to determine improved operating techniques to reduce the airspace requirements and pilot workload has been made and is reported. ${ }^{x}$

In this investigation, the supersonic transport was simulated by a fixed-based single-place cockpit and an analog computer arrangement. The equipment in the cockpit included the usual aircraft controls, with the exception that a side-arm controller was used for longitudinal and lateral control. The usual flight and navigation instrumentation was provided, and, in addition, for some tests an oscilloscope was

Received February 20, 1964.

* Aerospace Engineer. 


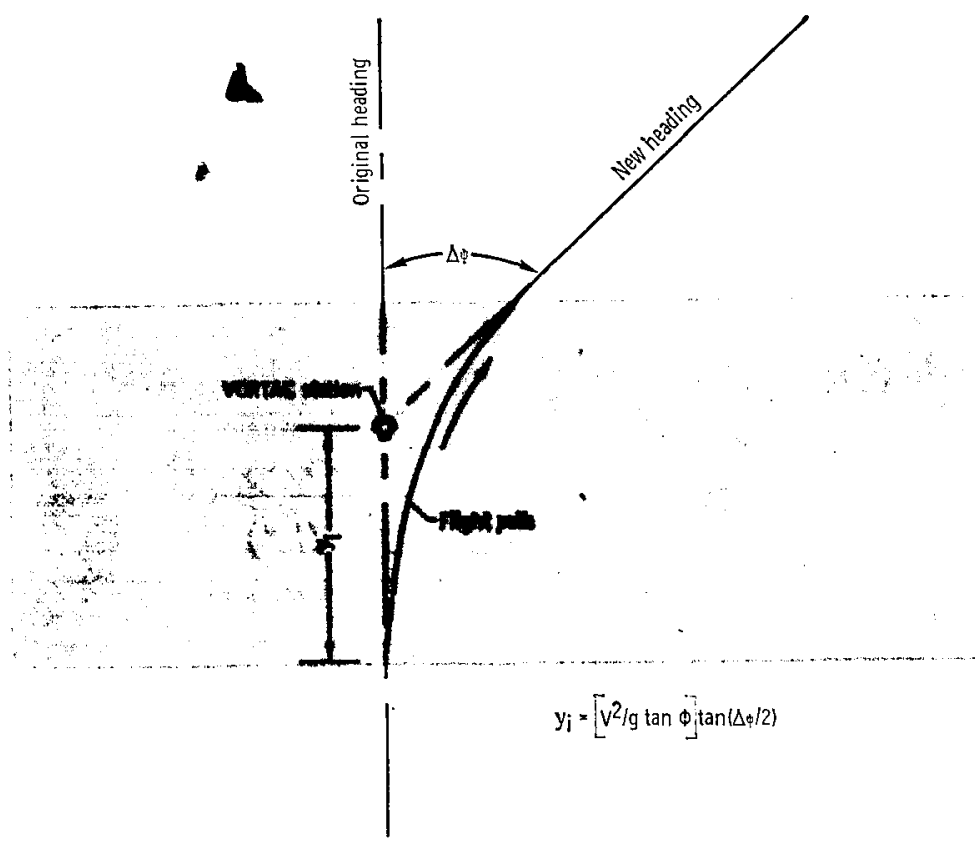

Fig. 1 Representation of calculated flight paths using lead-turn method.

used as a horizontal situation display, with the center of the grid representing a VORTAC station location and the course desired indicated by a line drawn on the face of the oscilloscope. The instantaneous horizontal position of the aircraft was generated by signals from the analog computer and displayed as a spot of light on the face of the oscilloscope. The selected physical characteristics of the supersonic transport programed in the analog computer represented a delta-wing canard-type design.

Simulated test runs were initiated at a Mach number of 3.0 at an altitude of $67,000 \mathrm{ft}$ on a northerly heading approximately 80 naut miles due South of the simulated VORTAC station. The piloting procedure was to fly along the $180^{\circ}$ radial to the station, make the required heading change at a specified bank angle, and terminate the run when the airplane was stabilized on the new course. The specified heading changes were made by using two different turn procedures. As is typical of present piloting practice, one set of turns was made by initiation of the turn after passing through the zone
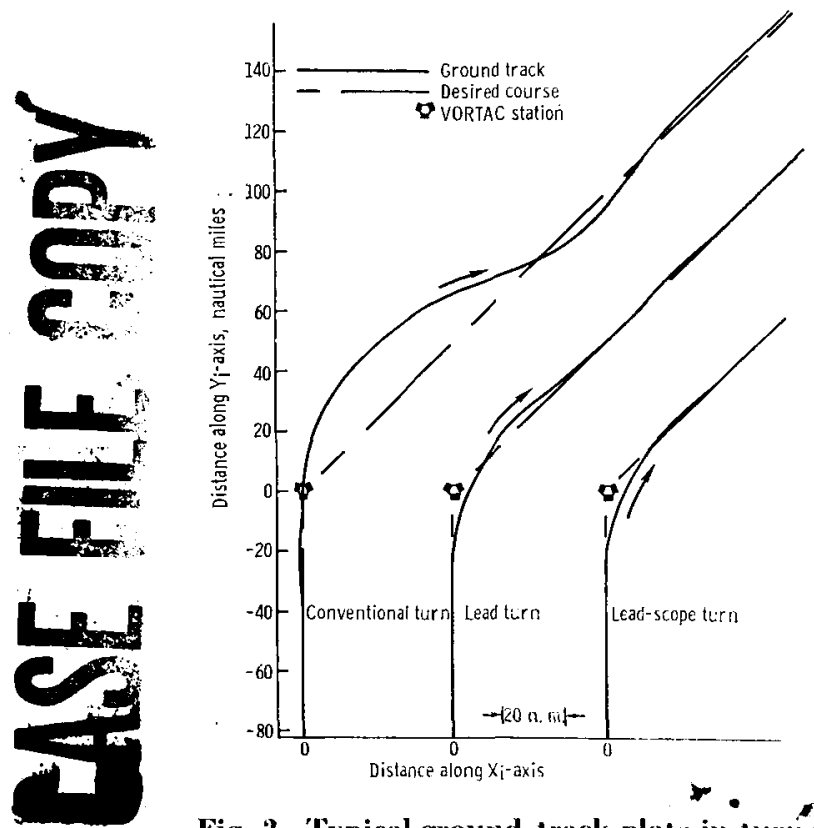

Fig. 2 'Typical ground-track plots in turís.

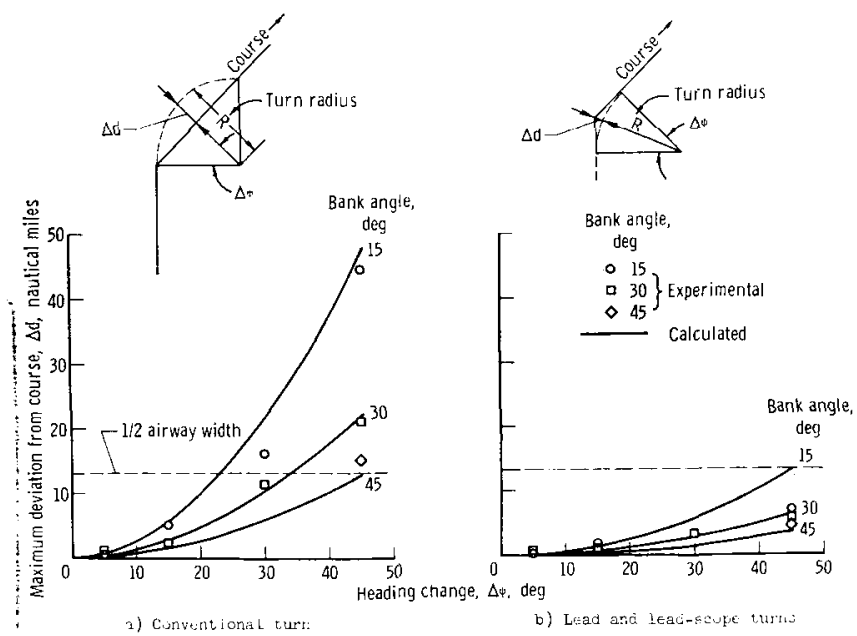

Fig. 3 Variation of maximum deviation from course with heading change for several bank angles; conventional, lead, and lead-scope turns.

of ambiguity over the station (conventional turns). A second set of turns (lead turns) was made by initiation of the turn at a predetermined slant range $l$ ahead of the station, $l$ being calculated by

$$
l=\left[\left(\frac{V^{2}}{g \tan \Phi} \tan \frac{\Delta \Psi}{2}\right)^{2}+h^{2}\right]^{1 / 2}
$$

where

$$
\begin{aligned}
l & =\text { slant range (lead distance), } \mathrm{ft} \\
V & =\text { true airspeed, fps } \\
\mathrm{g} & =\text { acceleration due to gravity, } 32.2 \mathrm{ft} / \mathrm{sec}^{2} \\
\Phi & =\text { bank angle } \\
\Delta \Psi & =\text { heading change } \\
h & =\text { altitude, } \mathrm{ft}
\end{aligned}
$$

The flight path for such a lead turn is along the arc of a circle which will bring the aircraft tangent to the new heading. A schematic representation of the flight path showing the ground distance $y_{i}$ corresponding to the slant-range-lead distance $l$ is shown in Fig. 1. Some lead turns were made using the horizontal situation display (lead-scope turns). Typical ground-track plots for the various types of turns are shown in Fig. 2.

The results of the investigation showed that the horizontal airspace used depended greatly on the type of turn employed. A comparison of the maximum distance that the aircraft deviated from course for both conventional and lead turns is shown in Fig. 3. Calculated values of aircraft deviation from course are also shown, and the agreement with experimental values indicates that these deviations can be calculated with sufficient accuracy. The much smaller deviations from course for the lead-type turns compared with the conventional turns are evident, with the deviations for lead turns for all the conditions that were tested falling well within one-half of the present high-altitude airway width.

Lead turns were also found to be preferred to conventiona! turns by the pilots, primarily because of the reduced number of maneuvers required to complete the turn. In addition, both deviations in altitude during the turn and pilot workload, as indicated by the number of control motions used in the turn, were found to be significantly less for the lead turns than for the conventional turns. The oscilloscope used as a horizontal situation display provided a means of more precise control of the flight path for the pilot, with an attendant reduction in workload.

\section{Reference}

1 Sawyer, R. H., "A simulator study of airspace requirements for the supersonic transport," NASA TN D-1964 (1963). 